\title{
Why a Digitally Enabled Minimum Data Set for Older Adults in Care Homes Might Improve Population Health and Well-Being Outcomes
}

\author{
Sally Fowler Davis* and Mandy Philbin \\ Sheffield Hallam University, UK
}

ISSN: 2578-0093

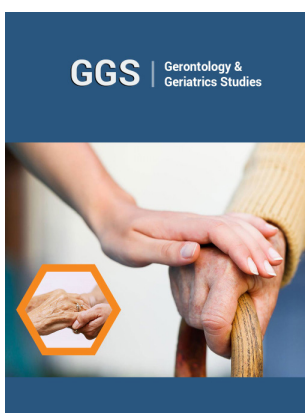

*Corresponding author: Sally Fowler Davis, Sheffield Hallam University, UK

Submission: 海 November 14, 2019

Published: 眥 November 20, 2019

Volume 5 - Issue 3

How to cite this article: Sally Fowler Davis, Mandy Philbin. Why a Digitally Enabled Minimum Data Set for Older Adults in Care Homes Might Improve Population Health and Well-Being Outcomes. Gerontol \& Geriatric stud.5(3). GGS.000613.2019.

DOI: $10.31031 /$ GGS.2019.05.000613

Copyright@ Sally Fowler Davis, This article is distributed under the terms of the Creative Commons Attribution 4.0 International License, which permits unrestricted use and redistribution provided that the original author and source are credited.

\section{Introduction}

The number of people requiring care home support is projected to rise in future years, and resident needs appear to be increasing, compounding the demand for care home beds and associated specialist services [1]. However, there is no routine and standardized method for measuring health and well-being outcomes of individuals within care homes in the UK. An accurate, low burden means of measuring and monitoring the health and well-being of residents [2] would allow careers, staff and planners a means of assessing health impact [3] and the effectiveness of care at delivering health benefits. Without this data, the cost and value of Care Home provision is only based on process and service data which is not enough for care planning.

The Care Homes sector represents a highly diverse range of organizational forms with workforce sustainability and leadership as critical issues in the drive for continuous improvement [4]. Outcomes-based commissioning and quality monitoring by family carers is driving the need for data about individual resident health and well-being [4] that demonstrates health impact [3] and weights the experience of residents in their home context [2]. Care Homes engage with numerous national initiatives [5] and some have achieved a shared appreciation of the trust and complexity issues associated with new ways of working [6]. A lack of health outcomes data has limited the population-based evaluation, cost release and service-resign. Planning and contracting must now focus on quality of life [7], prevention and health improvement [6,8].

\section{Literature}

Examples of implementing functional MDS are in the international literature. There is clear evidence for the validity of a functional and clinical data as a prerequisite for all epidemiological evidence-based studies [9-11].

Learning suggests that

a) Functional and social outcome measures describe the overall wellbeing of a resident $[9,10]$

b) data needs to be digital, visual and shared across the system to promote integrated care $[11,12]$ and

c) large sample sizes make statistical methods more consistent $[13,14]$.

A review of the Cochrane library (limited to the last few years) identified two MDS trials showing that incomplete identification data reduced the efficacy of the data set [13]. Studies of implementation of MDS $[14,15]$ indicate that standardized health metrics provide baseline data and enhance the capacity for quality improvement $[14,16]$ and for service evaluation, audit and research $[17,18]$. Health and care data for planning and commissioning for sector development [18] necessitates direct interpersonal contact, thoughtful co-production and sustained effort to scale change when introducing the MDS [19]. A tangible benefit such as a reduction in paperwork is a way of enhancing care home operations [19]. Enhancements to Care Homes depend on a MDS to enable a quality assessment of individual residents in care homes [20-23], particularly to evaluate the quality of care received, from a consumer perspective [23]. 


\section{Population outcome metrics}

The International Classification of Functioning (ICF) [24] is the World Health Organization's classification of health and healthrelated domains. As the functioning and disability of an individual occurs in a context, ICF also includes a list of environmental factors that support or limit the ability to live well. The outcome framework in the ICF seeks to measure health and disability at both individual and population levels and is the international standard to describe and measure health and disability. As a driver to focus on ability in context and not only on disease processes, the ICF supports the adoption of population outcomes that relate well to old age. The biopsychosocial model integrates different perspectives of health and wellbeing so rather than focusing on, for example, 'Alzheimer's' Disease' the focus is on an individual's ability or barriers to undertake activity and participation in the Care Home community.

This focus is more helpful because it aligns well to the priorities for social wellbeing that are known to care home managers and staff and to residents and their families. Relative concerns are with the day to day indicators of well-being, eating well, sharing a conversation, enjoying a piece of music, taking a walk and these outcomes are measurable and indicative of wellbeing, well recognized within social care [2]. There are a range of standardized assessments of functional outcomes that have been tested in older adult care settings, one the Therapy Outcome Measure [25] relates to activity and participation as described in the ICF.

\section{Collecting and sharing population outcome data}

Enabling technology is needed to support this different focus on Care Home day to day wellbeing as a proxy for health, especially if the data, when shared is to be used to monitor population outcomes and inform commissioning and contracting decisions. Digital innovation via the UK NHSX G Cloud provision has made it possible for digital data collection and transfer to be structured around the care home routine to enable people who live and work in care homes to familiarize themselves with the outcome metrics. Using 'Dumb' terminals (hardware i.e. tablets computers) to enable the data collection means that personal data is not stored on any device. Each home can develop their own understanding of the implementation of data collection so that it fits with their home routine and perhaps the corporate environment, whist retaining a commitment to health outcome measures embedded within the system. Pre-defined permissions and General Data Protection Regulation (GDPR) enabled, the data will be visible at individual and Care Home level. From there the 'Home' shares only anonymized data with other parts of the health system allowing for real-time comparison with local quality against outcomes. The MDS includes some usual demographic data permitted within GDPR that allows the commissioning organization to undertake multi-level modelling.

Digital monitoring of health outcomes is enabling via permissions in the G Cloud- (see UK Government ICT Framework agreement) identifiable to resident at Care Home level and pseudonymized to individual at source in the Care Home. The digital service provides a methodology to can enhance understanding of intervention effects this has implications for how easily an intervention can be replicated in another context. Simple multilevel modelling - can test the feasibility of using the data set for health impact assessment with different groups of older adults, for example, continuous monitoring of mobility levels [26] across the population of 85-95 year older residents either across an area or across the city. This could provide an indication of an important and known predictor of falls risk, thus enabling targeted prevention strategies in some or all homes. The G-Cloud framework as a means of collating and visualizing data at several levels will be critical to enable the identification of population data, allowing assessment of completeness and usefulness of the data relative to stakeholders.

\section{Conclusion}

The population outcomes MDS in digital format is a challenging and important opportunity for the people who live and work in the Sector and a development that needs to be carefully co-produced with providers, manager, residents and staff in close collaboration. The capacity in care homes, to collect and collate data is always a concern but has been achieved in a range of Care Home studies where the need to enhance capacity for quality or conversely to manage significant risk has justified the transformation cost [2731]. Digital inclusion is a significant by-product for the sector and a shared vision for joined up data and workforce planning will need to be evaluated as a factor in the return on investment towards achieving population health outcome data.

\section{References}

1. Stow D, Matthews FE, Barclay S, Iliffe S, Clegg A, et al. (2018) Evaluating frailty scores to predict mortality in older adults using data from population based electronic health records: case control study. Age Ageing 47(4): 564-569.

2. Netten A, Brown JB, Trukeschitz B, Towers AM, Welch E, et al. (2010) Measuring the outcomes of care homes: Final report. PSSRU Discussion Paper 2696(2).

3. Baylis A, Baker SP (2017) Enhanced health in care homes. Kings Fund.

4. h t t p s: / / a s s e t s.publis hi n g. s e r vi c e.gov.uk/ media/5941057be5274a5e4e00023b/care-homesmarket-studyupdate-paper.pdf

5. Cameron A, Lart R, Bostock L, Coomber C (2014) Factors that promote and hinder joint and integrated working between health and social care services: a review of research literature. Health Soc Care Community 22(3): 225-233.

6. https://www.england.nhs.uk/publication/the-framework-forenhanced-health-in-care-homes/

7. UK Government (2014) Care Act fact sheet.

8. Department of Health (2017) Next steps on the five-year forward view.

9. Onder G, Carpenter I, Soveri HF, Gindin J, Frijters D, et al. (2012) Assessment of nursing home residents in Europe: The services and health for elderly in long term care (SHELTER) study. BMC Health Serv Res 12(1): 5.

10. Tolson D, Rolland Y, Andrieu S, Aquino JP, Beard J, et al. (2011) The International Association of Gerontology and Geriatrics: a global agenda for clinical research and quality of care in nursing homes. J Am Med Dir Assoc 12(3): 184-189. 
11. Rolland Y, Kan GA, Hermabessiere S, Gerard S, Gillette SG, et al. (2009) Descriptive study of nursing home residents from the REHPA network. J Nutr Health Aging 13(8): 679-683.

12. Goossen WT, Epping PJ, Feuth T, Dassen TW, Hasman A, et al. (1998) A comparison of nursing minimal data sets. J Am Med Inform Assoc 5(2): 152-163.

13. Sawant A, Shah C, Badgujar L, Dang A (2015) How insurance claim data can help in health outcomes research: An Indian perspective. Value in Health 18(7): A730-A731.

14. Chi I, Chou KL, Kwan CW, Lam EKF, Lam TP (2006) Use of the minimum data set home care: a cluster randomized controlled trial among the Chinese older adults. Aging Ment Health 10(1): 33-39.

15. Fraser KD, Sales AE, Baylon MAB, Schalm C, Miklavcic JJ (2017) Data for Improvement and Clinical Excellence: a report of an interrupted time series trial of feedback in home care. Implementation Science 12(1): 66.

16. Sales AE, Schalm C, Baylon MAB, Fraser KD (2014) Data for improvement and clinical excellence: report of an interrupted time series trial of feedback in long-term care. Implementation Science 9(1): 161.

17. Rahman AN, Applebaum RA, Schnelle JF, Simmons SF (2012) Translating research into practice in nursing homes: Can we close the gap? Gerontologist 52(5): 597-606.

18. Rahman AN, Applebaum RA (2009) The nursing home minimum data set assessment instrument: manifest functions and unintended consequences-past, present, and future. Gerontologist 49(6): 727-735.

19. Mukamel DB (1997) Risk-adjusted outcome measures and quality of care in nursing homes. Med Care 35(4): 367-385.

20. Stone R, Harahan MF (2010) Improving the long-term care workforce serving older adults. Health Affairs 29(1): 109-115.
21. Panza F, Lozupone M, Solfrizzi V, Urso FD, Stallone R, et al. (2018) Comprehensive geriatric assessment in long-term care and nursing homes. Comprehensive Geriatric Assessment, pp. 47-56.

22. Mozley C (2017) Towards quality care: outcomes for older people in care homes. Routledge, London, United Kingdom.

23. Milte R, Ratcliffe J, Bradley C, Shulver W, Crotty M (2017) Evaluating the quality of care received in long-term care facilities from a consumer perspective: development and construct validity of the consumer choice index six-dimension instrument. Ageing \& Society 39(1): 138-160.

24. International classification of functioning for disability and health.

25. Enderby P, John A, Petheram B (2013) Therapy outcome measures for rehabilitation professionals: speech and language therapy, physiotherapy, occupational therapy. ( $2^{\text {nd }}$ edn), John Wiley \& Sons, New Jersey, United States.

26. Bischoff HA, Stähelin HB, Monsch AU, Iversen MD, Weyh A, et al. (2003) Identifying a cut-off point for normal mobility: a comparison of the timed 'up and go' test in community-dwelling and institutionalized elderly women. Age and ageing 32(3): 315-320.

27. Lawless P, Pearson S (2012) Outcomes from community engagement in urban regeneration: Evidence from England's New Deal for Communities Programme. Planning Theory \& Practice 13(4): 509-527.

28. Burns D, Hyde P, Killett A (2013) Wicked problems or wicked people? Reconceptualizing institutional abuse. Sociol Health Illn 35(4): 514-528.

29. Killett A, Burns D, Kelly F, Brooker D, Bowes A, et al. (2016) Digging deep: how organizational culture affects care home residents' experiences. Ageing \& Society 36(1): 160-188.

30. NHS England (2017) Next steps on the five-year forward view.

31. Curtis L, Netten A (2005) Unit costs and health and social care. PSRU. 